\title{
Heterogeneous Stem Cells in Skin Homeostatis and Wound Repair
}

\author{
Anna Meiliana ${ }^{1,2, *}$, Nurrani Mustika Dewi², Andi Wijaya ${ }^{2,3}$ \\ ${ }^{1}$ Postgraduate Program in Clinical Pharmacy, Padjadjaran University, Jl. Eijkman No.38, Bandung, Indonesia \\ ${ }^{2}$ Prodia Clinical Laboratory, Jl. Cisangkuy No.2, Bandung, Indonesia \\ ${ }^{3}$ Postgraduate Program in Clinical Biochemistry, Hasanuddin University, Jl. Perintis Kemerdekaan Km.10, Makassar, Indonesia \\ *Corresponding author. E-mail: anna.meiliana@prodia.co.id
}

Received date: Jun 16, 2015; Revised date: Jun 25, 2015; Accepted date: Jun 29, 2015

\section{Abstract}

B ACKGROUND: The skin protects mammals from insults, infection and dehydration and enables thermoregulation and sensory perception. Various skin-resident cells carry out these diverse functions. Constant turnover of cells and healing upon injury necessitate multiple reservoirs of stem cells. The skin is a complex organ harboring several distinct populations of stem cells and a rich array of cell types. Advances in genetic and imaging tools have brought new findings about the lineage relationships between skin stem cells and their progeny. Such knowledge may offer novel avenues for therapeutics and regenerative medicine.

CONTENT: In the past years, our view of the mechanisms that govern skin homeostasis and regeneration have markedly changed. New populations of stem cells have been identified that behave spatio-temporally differently in healthy tissues and in situations of damage, indicating that a great level of stem cell heterogeneity is present in the skin. There are believed to be distinct populations of stem cells in different locations. The lineages that they feed are normally constrained by signals from their local environment, but they can give rise to all epidermal lineages in response to appropriate stimuli. Given the richness of structures such as blood vessels, subcutaneous fat, innervation and the accumulation of fibroblasts under the upper parts of the rete ridges (in the case of human skin), it is reasonable to speculate that the microenvironment might be essential for interfollicular epidermal homeostasis. The bloodstream is probably the main source of long-range signals reaching the skin, and cues provided by the vascular niche might be essential for skin homeostasis.

SUMMARY: A key function of the interfollicular epidermis is to act as a protective interface between the body and the external environment, and it contains several architectural elements that enable it to fulfill this function. All elements of the epidermis play active roles in regulating skin function, which might not have been anticipated from their role in maintaining skin integrity. Skin cell research benefits from the integration of complementary technologies and disciplines. How skin function is regulated and how it may be possible to intervene to treat a variety of skin conditions. ultimately also impairing the maintenance of self-renewing satellite cells. Therefore, only anti-aging strategies taking both factors, the stem cell niche and the stem cells per se, into consideration may ultimately be successful.

KEYWORDS: epidermis, hair follicle, fibroblast, skin stem cells, homeostasis, regeneration

Indones Biomed J. 2015; 7(2): 87-100

\section{Introduction}

Skin is frequently referred to as the largest organ in the body. The skin is a multilayered organ that protects the organism against external aggressions. The outermost layer of the skin is the epidermis, which has a high turnover rate owing to the continuous shedding of the uppermost cornified cells. It is also perhaps the tissue that withstands the highest number of injuries because of this inherent function. As in every tissue 
with a high degree of turnover, the role of its resident stem cells is crucial for maintaining the equilibrium between cell loss and cell division (homeostasis), as well as for repairing damaged areas.(1)

Epidermal stem cells ensure that skin homeostasis is maintained. Murine epidermal stem cells are located either at the permanent portion of the hair follicle, termed the bulge, and are exclusively responsible for hair cycling (25 ); or at the junction between the epidermis and the hair follicle (isthmus), and feed into the epidermis and sebaceous glands (6-8). In addition, a continuous proliferation of basal interfollicular epidermal cells ensures daily epidermal maintenance. $(9,10)$ Different resident skin stem cell pools contribute to the maintenance and repair of the various epidermal tissues of the skin, including interfollicular epidermis (IFE), hair follicles, and sebaceous glands.(11)

In the adult skin, IFE and sebaceous glands are subject to constant self-renewal, whereas hair follicles cycle between growth, involution, and resting phases.(12) Under normal conditions, these three skin cell populations are each believed to be maintained by their own discrete stem cells. (13) When tissue homeostasis is disrupted, however, any of the three stem cell populations is capable of producing all three structures. $(6,13,14)$

Skin injuries are a part of everyday life, and efficient wound repair is vital to restore the protective barrier function of the skin. Defects associated with cutaneous wound repair represent a tremendous burden for patients and health systems. Understanding the basic mechanisms of epithelial repair in human skin after wounding is a necessary first step in the design of therapeutic strategies with the objective of restoring burdening wound-healing defects.(15)

Skin aging involves increased susceptibility to injury and infection, reduced wound healing, loss of dermal elasticity, poor epidermal barrier maintenance, wrinkling, hair loss, and increased cancer risk.(16) Epidermal stem cells are retained throughout life despite significant age-associated changes in dermal thickness, epidermal proliferation, and peripheral immune cell abundance. These findings suggest that local environmental rather than stemcell-intrinsic factors influence skin aging.(17)

In the past years, our view of the molecular and cellular mechanisms that ensure the self-renewal of the skin has dramatically changed. Several populations of stem cells have been identified that differ in their spatiotemporal contribution to their compartment in steady-state and damaged conditions, suggesting that epidermal stem cell heterogeneity is far greater than previously anticipated. There is also increasing evidence that these different stem cells require a tightly controlled spatial and temporal communication between other skin residents to carry out their function.(1)

\section{Skin Cell Biology}

Mammalian skin forms the outer covering of the body and consists of two major layers (Figure 1). The upper layer is an epithelium called the epidermis, and the lower layer is a connective tissue called the dermis. The epidermis comprises a multilayered epithelium, IFE, and associated (adnexal) structures, which are hair follicles, sebaceous glands, and sweat glands. Key functions of the epidermis are the formation of a protective interface with the external environment, lubrication of the skin with lipids, and thermoregulation by hairs and sweat. Each function depends on non-dividing, terminally differentiated keratinocytes that die and are shed from the body. These differentiated cells are replenished through a variety of stem cell populations in different epidermal locations.(18) Under steady-state conditions, each stem cell compartment produces a subset of differentiated epidermal cells, but when the cells are transplanted or the skin is damaged or otherwise manipulated experimentally, most stem cells can contribute to the full range of differentiated epidermal lineages.(19)

The epidermis is separated from the dermis by a basement membrane, an extracellular matrix (ECM) that is rich in type IV collagen and laminin. The main resident cell type of the dermis is the fibroblast. The dermis is organized into three layers. The layer closest to the epidermis is the papillary layer, and beneath that lies the reticular layer. Fibroblast density is higher in papillary dermis, and the reticular dermis is characterized by an abundance of fibrillar collagen. The deepest dermal layer, historically termed the hypodermis, is characterized by a thick layer of white adipocytes. In addition to the three main dermal layers, there are two other mesenchymal structures in the dermis that are important for skin function. These are the dermal papilla, a cluster of cells at the base of the hair follicle that control the hair follicle cycle, and the arrector pili muscle, a smooth muscle that inserts into the basement membrane at a specific point in the hair follicle and, on contraction, causes the hair follicles to become erect.(19)

Although epidermal epithelial cells (keratinocytes) and dermal fibroblasts are the most abundant cell types in the skin, there are several other key cell types that are either permanent residents of the tissue or traffic through the skin. These include the cells of the peripheral nervous system (20) and blood vessels, melanocytes (21), and cells of the 
innate and adaptive immune system (22).

Hair follicles are notable appendages of the epidermis. In addition to generating hairs that facilitate thermal regulation, hair follicles also serve as anchors for sensory neurons, arrector pili muscles and blood vessels. Hair follicles undergo cycles of regeneration and rest driven by stem cells located in a region known as the bulge, and in a cluster of cells below the bulge known as the hair germ.(23)

The skin, our largest organ, encompasses the entire body and mediates our sense of touch. Neurophysiologically complex, the skin is innervated by a wide variety of sensory neuron subtypes, including nociceptors, which sense painful stimuli; pruriceptors, which convey itch; thermoreceptors, which register temperature information; and low-threshold mechanoreceptors, which encode nonpainful mechanical stimuli, or touch. We use our sense of touch to recognize and manipulate objects, to communicate and socially interact with one another, to appreciate the textures of the foods we eat, for procreation and sexual pleasure, and in maternal nursing. The cutaneous end organs and the mechanosensory neurons that innervate them have evolved to underlie a range of sensory functions, as evidenced by the multitude of skin type specializations that are each innervated by a distinct array of sensory neuron subtypes, reflecting the diversity of functions of touch neurons.(20)

Melanomas arise from malignant transformation of melanocytes, the melanin-producing cells of the skin, eye, mucosal epithelia, and meninges that are responsible for pigmentation and photo protection. Melanocytes are derived from neural crest progenitors, and their development is modulated by the receptor tyrosine kinase
c-Kit and microphthalmia-associated transcription factor. (24) Melanocytes produce two main types of pigment: brown/black eumelanin and red pheomelanin. Eumelanin is the photo-protective pigment that provides ultraviolet radiation (UVR) attenuation. Pigment synthesis is stimulated by binding of a-melanocyte-stimulating hormone to melanocortin 1 receptor (MC1R) on melanocytes.(21) $\mathrm{MC1R}$ is a major determinant of pigmentation, and lossof-function polymorphisms result in impaired eumelanin production, with the most severe loss-of-function alleles producing red hair and fair skin.(24) In addition to basal pigmentation, acquired pigmentation can be elicited by stimuli such as UVR.(25)

Human skin, the body's largest organ, functions as a physical barrier to bar the entry of foreign pathogens, while concomitantly providing a home to myriad commensals. Over a human's life span, keratinized skin cells, immune cells, and microbes all interact to integrate the processes of maintaining skin's physical and immune barrier under homeostatic healthy conditions and also under multiple stresses, such as wounding or infection. The intricate interactions of microbes and immune cells on the skin surface and within associated appendages to regulate this orchestrated maturation in the context of both host physiological changes and environmental challenges.(22)

Although clinicians have long felt this to be evident, it has only relatively recently become clear that, besides the 'gut-brain axis', there is also a 'brain-skin axis', whose molecular key players are increasingly understood.(2629) Interestingly, a number of gastrointestinal peptides (e.g., calcitonin gene-related peptide, vasoactive intestinal

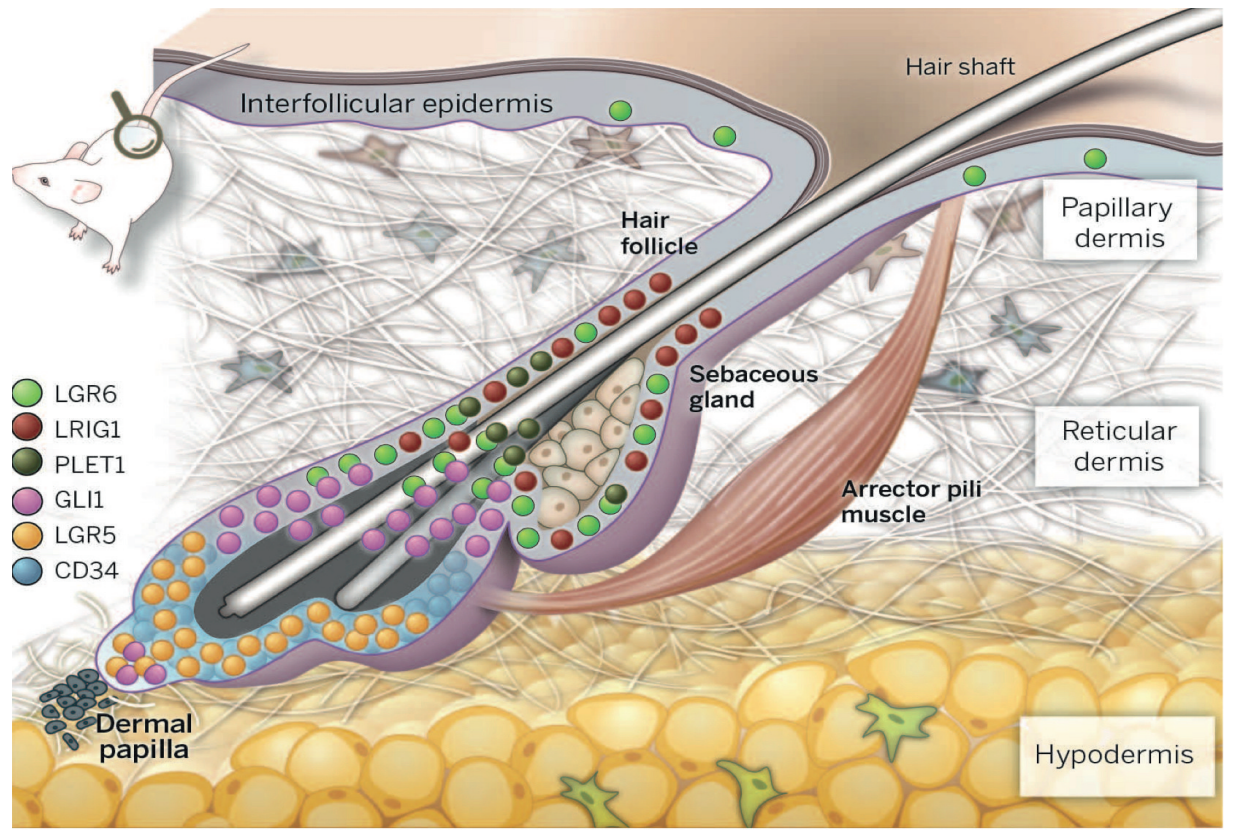

Figure 1. Mouse back skin. Markers of different epidermal stem cell populations (LGR6, LRIG1, PLET1, GLI1, LGR5, and CD34) are shown. LGR6 and LRIG1 are expressed in the hair follicle isthmus, whereas CD34 and LGR5 are bulge markers. (19) (Adapted with permission from American Association for the Advancement of Science). 
peptide) have also been detected in intra-cutaneous nerve fibres.(30) The 'gut-brain axis' and this more recently documented 'gut-skin axis' are intimately linked with each other.(31)

\section{Skin Stem Cells and Their Niches}

In mammals, the skin's protective barrier is composed of a stratified epidermis (Figure 2). The IFE between hair follicles is exposed to many external insults, such as ultraviolet light, chemicals, allergens and traumatic injuries. To withstand these physical stresses, the epidermal cells, called keratinocytes, form a dense cytoskeletal infrastructure of $10-\mathrm{nm}$ intermediate filaments composed of the keratin subfamily of proteins. Keratin filaments are highly enriched in the vertebrate epidermis and its appendages, but not in the surface epithelium of organisms such as insects, which instead secrete a protective outer shell.(23)

The epidermis is a stratified structure. Self-renewing stem cells reside within the basal layer, which adheres through $\alpha 3 \beta 1$ and $\alpha 6 \beta 4$ integrins to an underlying basement membrane of laminin-5-rich ECM that separates the epidermis from the underlying dermis. Secreted factors such as fibroblast growth factor (FGF)-7, FGF-10, insulin growth factor (IGF), epidermal growth factor (EGF) ligands and transforming growth factor (TGF)- $\alpha$ from dermal fibroblasts promote the proliferation of basal epidermal cells.(23)

The epidermis comprises the IFE, hair follicles, sebaceous glands and sweat glands. Each of these tissues has its resident stem cells. The IFE is defined as the region of stratified epidermis flanked by hair follicles. The classic hypothesis of interfollicular stem cell behaviour, based on early labelretaining studies, stated that stem cells located at the basal layer give rise to shortlived progenitors that undergo several rounds of division, known as transitamplifying cells. These cells would amplify the keratinocyte population and migrate upwards as they differentiate, constituting one epidermal proliferative unit.(32,33)

Recent studies suggest, however, that the basal layer of the mouse IFE is heterogeneous and also contains basal cells that do not behave like committed progenitors. The IFE contains a reservoir of quiescent basal cells, predominantly for regenerative purposes, that is possibly compartmentalized around the hair follicles. A molecular analysis of these two populations revealed that committed progenitors express lower levels of stem cell markers, such as $\alpha 6$ and $\beta 1$ integrin, and higher levels of proteins controlling the epidermal and keratinocyte differentiation programme, like Notch 3, grainyhead-like-3 and some members of the SPPR family. In addition, committed progenitors show higher rates of proliferation than the quiescent stem cell population from which they originate.(34)

Interestingly, the higher expression of $\beta 1$ integrin by quiescent mouse interfollicular stem cells has also been observed for human epidermal stem cells, with quiescent and proliferative pools being distinguished by several markers. (34) For instance, quiescent human interfollicular stem cells not only express higher levels of $\alpha 6$ and $\beta 1$ integrins $(35,36)$

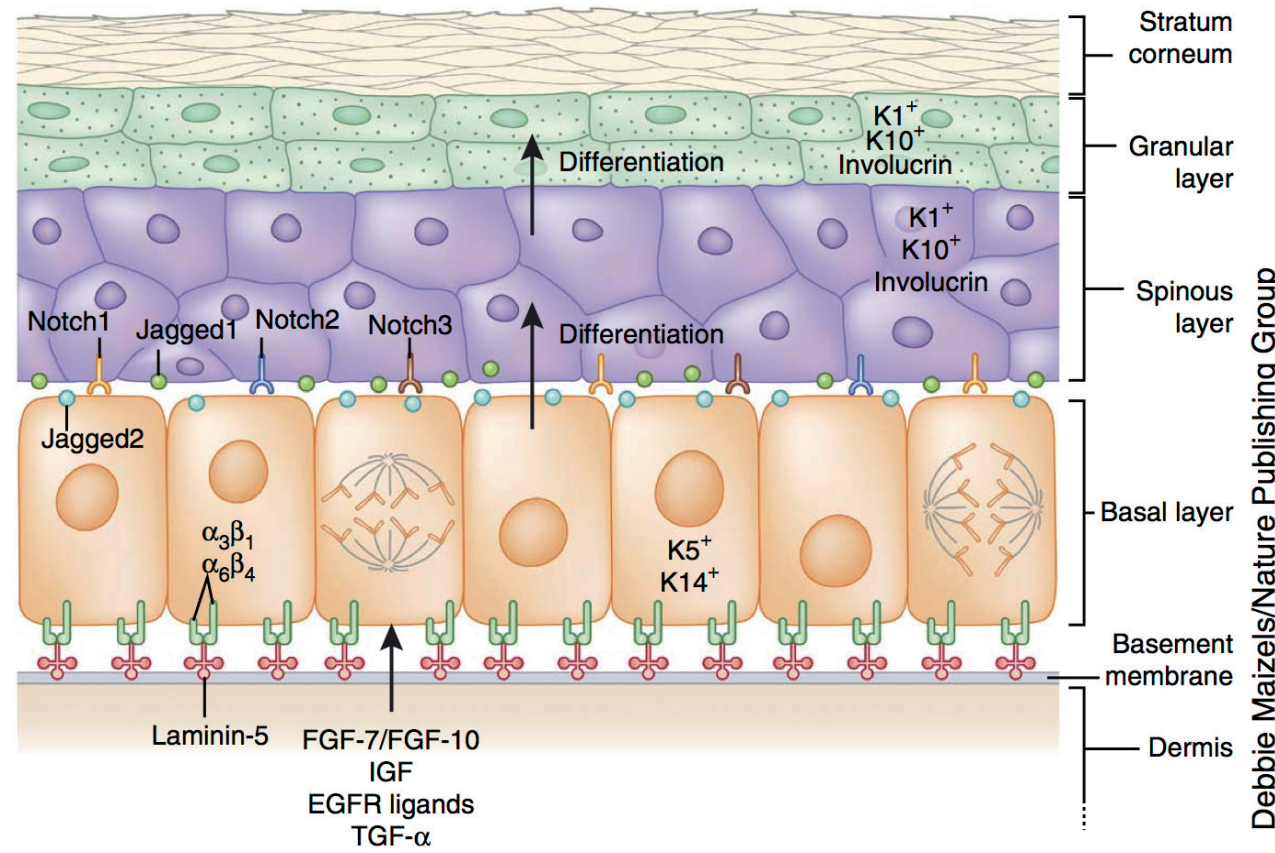

Figure 2. Mouse back skin. Markers of different epidermal stem cell populations (LGR6, LRIG1, PLET1, GLI1, LGR5, and CD34) are shown. LGR6 and LRIG1 are expressed in the hair follicle isthmus, whereas CD34 and LGR5 are bulge markers.(19) (Adapted with permission from American Association for the Advancement of Science). 

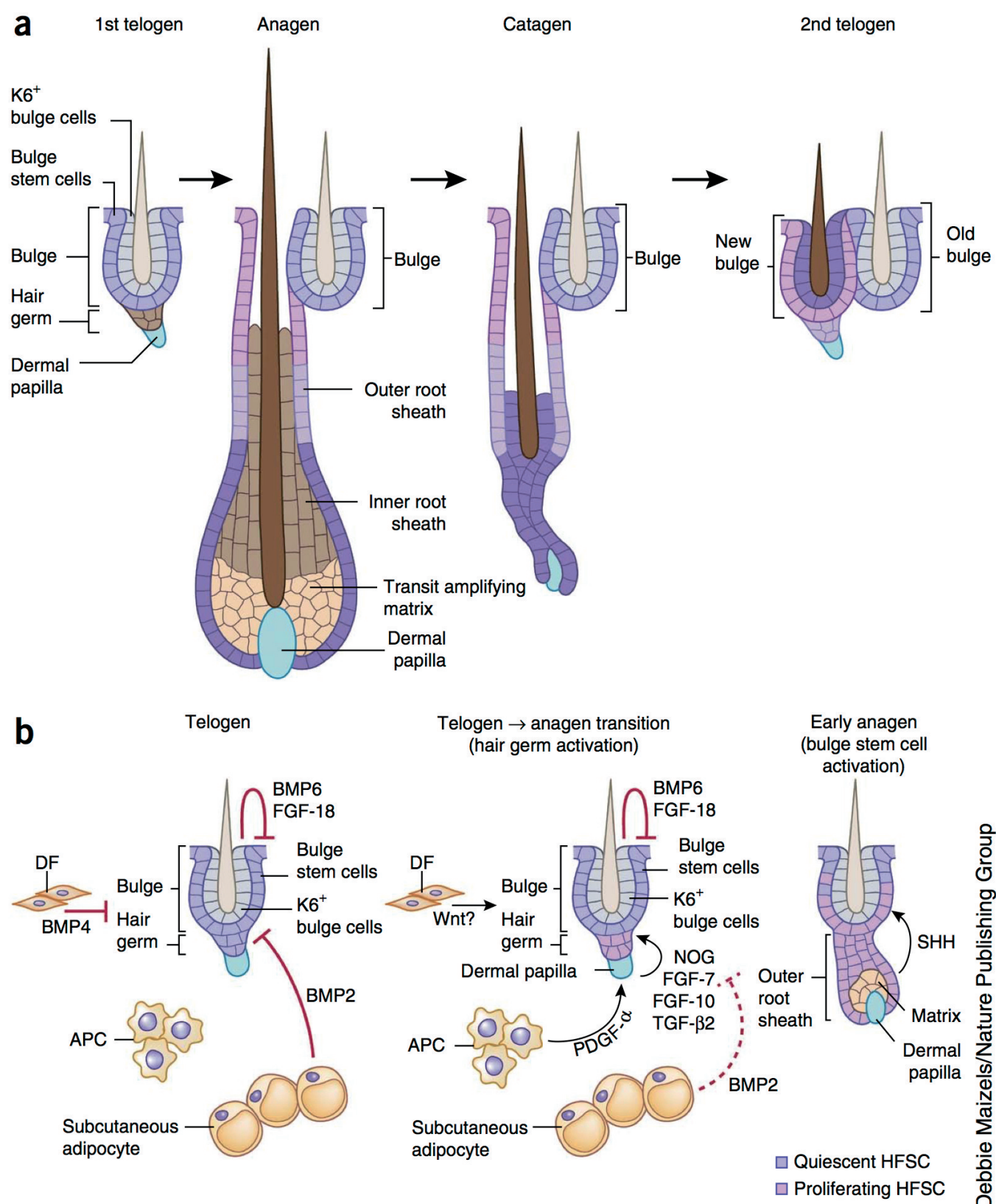

Figure 3. Hair follicle lineage and niche signals regulate hair follicle stem cells.(23) (Adapted with permission from Nature Publishing Group).

but also lower levels of the transferrin receptor CD71 (37). Quiescence of human interfollicular stem cells also relies on the activity of Delta 1 (38), melanomaassociated chondroitin sulphate proteoglycan (MCSP), leurich repeats and immunoglobulinlike domains 1 (LRIG1) (39), the polycomb protein chromobox protein homologue 4 (CBX4) (40) or on low levels of desmoglein 3 (DSG3) (41) and EGF receptor $(40,42)$.

Unlike the epidermis, which regenerates continually, hair follicles undergo cycles of growth (anagen), degeneration (catagen) and rest (telogen) (Figure 3). In mice, the first two cycles are synchronized, making hair follicles an ideal system for understanding how stem cells interact with progeny and heterologous cell types in the niche to transition between quiescence and regeneration. Hair follicle stem cells can be subdivided into two populations that share similar molecular signatures: a quiescent one located in the bulge (Bu-SCs) and a primed population within the hair germ just below the bulge, which is more prone to proliferation.(43) Previous lineage, tracing studies have demonstrated that these two populations are responsible for initiating hair growth $(3,44,45)$, and recently live imaging has provided a more precise means of delineating their relative contributions to these early steps (46). Neither Bu- 
SCs nor hair germ give rise to differentiated cells directly. (23) Bulge stem cells give rise to the cycling portion of the hair follicle in every anagen phase $(3,4,43,44,47)$ and regenerate the entire hair follicle and IFE when transplanted $(3,4,48-54)$. Among the bulge stem cell population, the first level of heterogeneity stems from the fact that only a portion of bulge stem cells is activated during anagen and that different bulge stem cells show distinct propensity to proliferate.(1)

Circadian rhythms also have a role in determining the differential response of bulge stem cells to activating stimuli. It has been shown recently that the expression of specific signals controlling the activation, quiescence and differentiation of bulge stem cells, including elements of the Wnt, TGF- $\beta$ and Notch signalling pathways, are under circadian control. Interestingly, two populations of clockantiphasic stem cells coexist in telogen hair follicles, one that is prone to activation (Wnt responsive high) and one that is predisposed to remain quiescent (Wnt responsive low). The circadian expression of proteins involved in Wnt signalling thus dictates which bulge stem cells will become active and which will remain dormant during anagen.(10)

Hair follicles connect with the epidermis through the junctional zone, which lies immediately above the bulge, and the isthmus, which extends from the junctional zone up to the IFE. These two areas have recently attracted much attention, as they seem to contain several subsets of specialized stem cells (Figure 4).(1)

Adult stem cells reside in niches that provide spatially distinct microenvironments for stem cell maintenance and function. The conceptual framework for stem cell niches, their compositions and their operating logistics is constantly being updated. Initially, niches were thought to be composed solely of heterologous cell populations that originate from a lineage different from the stem cells they regulate.(55) Recent studies have added several important modifications: differentiated progeny and stem cells can coexist within a niche, suggesting that niche signals alone are not sufficient to dictate 'stemness' $(44,56)$; downstream progeny of stem cells can regulate their stem cell parents and thus become a component of the niche $(57,58)$; and communications between stem cells and their niches are reciprocal, as stem cells may also regulate the assembly and maintenance of their niches (59).

New evidence indicates that hair follicle stem cells rely on both cellautonomous mechanisms and their microenvironment for their correct functioning. Bulge stem cells retain their identity and potential to regenerate hair follicles upon transplantation even when having been passaged in culture, suggesting that their identity can be maintained, at least in the short term, without any surrounding niche cues.(52,60) However, transplanted bulge stem cells recruit and regenerate a new niche. $(4,52,61)$ This might depend on the secretion of specific factors and extracellular or transmembrane proteins, both of which are enriched in the transcriptome signature of bulge stem cells. This specialized environment subsequently dictates the behaviour of bulge stem cells.(62) Further underscoring the importance of the niche, new studies indicate that bulge stem cells communicate with various cell types, including specialized dermal fibroblasts, muscle cells, adipocytes and neurons.(1)

\section{Skin Homeostatis and Regeneration}

At the surface of body organs, epithelial tissues must withstand harsh external environments. To do so, they rely heavily upon stem cells to replenish and repair wounds and replace the many cells that die from this wear and tear. Tissue homeostasis and wound repair are ensured by stem cells, located within specialized microenvironments, referred to as niches. Each niche is tailored to accommodate the regenerative needs of its tissue. Some tissues, for instance, skin epithelium, harbor multiple stem cell niches, each with their own responsibility for maintaining cellular balance within their particular domain.(64)

Accumulating evidence on bone marrow, intestinal stem cell crypts, and hair follicles suggests that stem cells often exist in two distinct states based upon their relative activity and/or their ease of activation during homeostasis and/or wound induced regeneration. Recent studies on the hair follicle reveal that signals emanating from both heterologous niche cells and from lineage progeny influence the timing and length of stem cell activity. This in turn can profoundly affect the amount of tissue regenerated.(64)

In homeostasis, cells lost during the course of turnover must be perfectly compensated by cells generated in the basal layer. Different theories have been proposed to explain how this balance is achieved.(11) On the basis of morphological and proliferation studies, it has been proposed that the skin IFE is organized into discrete 'epidermal proliferative units' (EPUs), comprised of slow-cycling stem cells together with around 10 transit-amplifying cell progeny, which undergo terminal differentiation after a fixed number of cell divisions.(64-67) Following the clonal marking of IFE cells by retroviruses $(49,68-70)$ or mutagens $(71,72)$, longlived columns of labelled IFE cells that span the epidermis from the basal layer to the top of the cornified layer appear, 
lending support to the concept of EPUs. By contrast, the quantitative analysis of lineage tracing data in IFE using a ubiquitous promoter suggests that tissue is maintained by a single, equipotent, committed progenitor cell population in which the balance between proliferation and differentiation follows from seemingly random cell fate decisions. $(9,73)$ After wounding, only stem cells contribute substantially to the repair and long-term regeneration of the tissue, whereas committed progenitor cells make a limited contribution.(34)

The primary source of cell renewal is through proliferation of stem cells $(74,75)$; however, there seems to be some plasticity between stem cells and their early progeny, as most basal keratinocytes maintain their regenerative potential and are capable of regenerating epidermis when activated by appropriate stimuli or transplanted into an in vivo setting.(76) It is unclear, however, at what point the keratinocytes lose their regenerative capacity. Certainly, by the time the nucleus of the cells has begun to disintegrate, the cells have lost the capacity to reenter the proliferative cycle.(77)

LRIG1 is a marker of human IFE stem cells and helps maintain stem cell quiescence. In mouse epidermis, LRIG1 defines the hair follicle junctional zone adjacent to the sebaceous glands and infundibulum. LRIG1 is a Myc target gene; loss of LRIG1 increases the proliferative capacity of stem cells in culture and results in epidermal hyperproliferation in vivo. LRIG1-expressing cells can give rise to all of the adult epidermal lineages in skin reconstitution assays. However, during homeostasis and on retinoic acid stimulation, they are bipotent, contributing to the sebaceous gland and IFE. $\beta$-catenin activation increases the size of the junctional zone compartment, and loss of LRIG1 causes a selective increase in $\beta$-catenin-induced ectopic hair follicle formation in the IFE. These suggest that LRIG1-positive cells constitute a previously unidentified reservoir of adult mouse IFE stem cells.(7)

Organ replacement regenerative therapy is expected to provide novel therapeutic systems for donor organ transplantation, which is an approach to treating patients who experience organ dysfunction as the result of disease, injury or aging.(78) Concepts in current regenerative therapy include stem cell transplantation and two-dimensional uniform cell sheet technologies, both of which have the potential to restore partially lost tissue or organ function. (79-81) The development of bioengineered ectodermal organs, such as teeth, salivary glands, or hair follicles may be achieved by reproducing the developmental processes that occur during organogenesis.(82-86)

In the age of stem cell engineering it is critical to understand how stem cell activity is regulated during regeneration. Hairs are mini-organs that undergo cyclic regeneration throughout adult life (87), and are an important model for organ regeneration. Hair stem cells located in the follicle bulge (88) are regulated by the surrounding microenvironment, or niche (89). The activation of such stem cells is cyclic, involving periodic $\beta$-catenin activity. (90-93) In the adult mouse, regeneration occurs in waves in a follicle population, implying coordination among adjacent follicles and the extra follicular environment.(94)

After morphogenesis, various stem cell types are maintained in certain regions of the follicle. For instance, follicle epithelial cells are found in the follicle stem cell niche of the bulge region $(51,52)$; multipotent mesenchymal precursors are found in dermal papilla cells $(95,96)$; neural crest-derived melanocyte progenitors are located in the subbulge region (97-99), and follicle epithelial stem cells in the bulge region that is connected to the arrector pili muscle $(59,100)$. The follicle variable region mediates the hair cycle, which depends on the activation of follicle epithelial stem cells in the bulge stem cell niche during the telogen-toanagen transition. $(43,101)$ This transition includes phases of growth (anagen), apoptosis-driven regression (catagen) (102) and relative quiescence (telogen) (87), whereas the

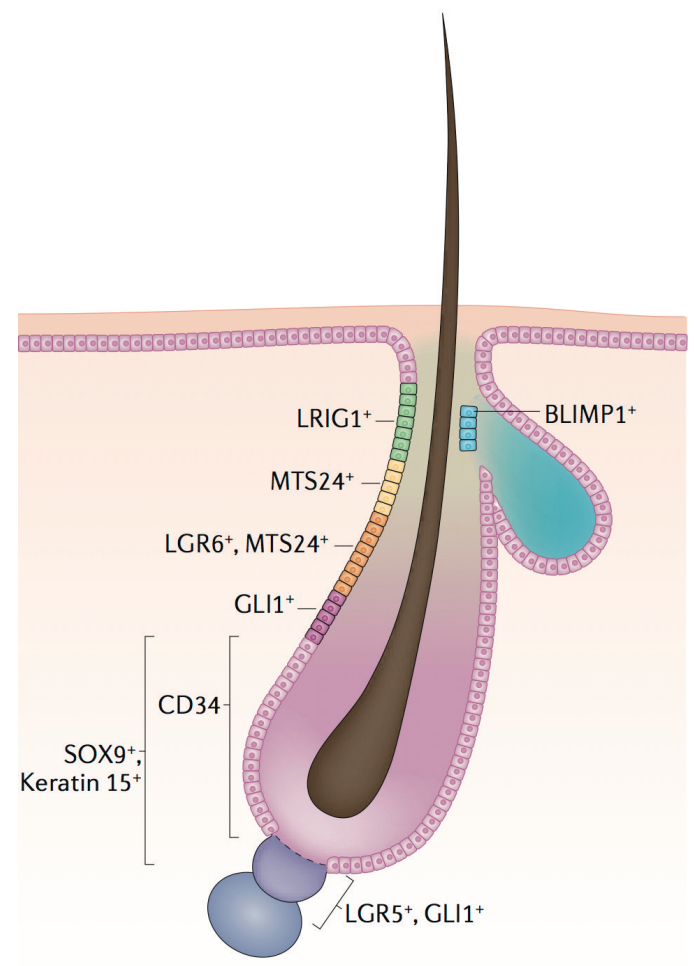

Figure 4. Hair follicle stem cell pools. Hair follicles contain several pools of spatially distributed stem cells that are defined by unique molecular signatures and differentially contribute to hair follicle cycling.(1) (Adapted with permission from Nature Publishing Group). 
organogenesis of most organs is induced only once during embryogenesis (103).

To achieve hair follicle regeneration in the hair cycle, it is thought to be essential to regenerate the various stem cells and their niches. $(86,104)$ Many studies have attempted to develop technologies to renew the variable lower region of the hair follicle $(105,106)$, to achieve de novo folliculogenesis via replacement with hair follicle-inductive dermal cells (107), and to direct the self-assembly of skinderived epithelial and mesenchymal cells (77,108-112). Toyoshima, et al. demonstrate fully functional orthotopic hair regeneration via the intracutaneous transplantation of bioengineered hair follicle germ.(61)

Melanocyte stem cells (McSCs) intimately interact with epithelial stem cells (EpSCs) in the hair follicle bulge and secondary hair germ. Together, they undergo activation and differentiation to regenerate pigmented hair. However, the mechanisms behind this coordinated stem cell behavior have not been elucidated. Rabbani, et al. identified Wnt signaling as a key pathway that couples the behavior of the two stem cells. EpSCs and McSCs coordinately activate Wnt signaling at the onset of hair follicle regeneration within the secondary hair germ.(113)

Skin regeneration is an important area of research in the tissue engineering (TE) field, especially for massive skin loss cases, where current treatments are yet not capable of inducing permanent satisfying skin regeneration. (80) To achieve an effective healing, skin TE products must attach well to the wound bed, be supported by new vasculature, integrate with the surrounding host tissues, be non-immunogenic, and be capable of self regeneration with minimum scar tissue, with reduced patient pain and discomfort, and yet importantly, manufactured with a good cost-benefit ratio. $(114,115)$ Thus, in order to meet the need for maintaining keratinocytes in an early differentiation state, the revolutionary approach in skin TE comprises the use of stem cells, guarantying also an unlimited source of biological material, crucial for large full-thickness skin defects.(115)

\section{Cutaneous Wound Healing}

The skin, as the body's external epithelium, sustains and repairs injuries throughout a lifetime. This vital role is affected by a wide variety of factors that influence skin wounding and the speed and quality of healing. Surgical incisions, thermal burns, and chronic ulcers are among the conditions in which wound healing plays a critical role. (116-118) In addition to acute wounds, there has been a steady rise in chronic skin wounds such as pressure ulcers and diabetic foot ulcers, which now affect more than $1 \%$ of all people during their lifetime.(119) Advances in understanding the molecular and cellular basis of cutaneous wound healing will be important for improved wound therapy and prevention.

Cutaneous wound healing is classically divided into four overlapping stages: hemostasis, inflammation, proliferation, and remodeling. Each stage is characterized by key molecular, cellular, and physiologic events, which are orchestrated in large part by signaling among hematopoietic, immunologic, and resident skin cells. These stages have been reviewed in detail (120) and are summarized in Figure 5.(121)

A key role for eccrine sweat glands in reconstituting the epidermis after wounding in humans. More specifically, eccrine sweat glands generate keratinocyte outgrowths that ultimately form new epidermis; eccrine sweat glands are the most abundant appendages in human skin, outnumbering hair follicles by a factor close to 3 ; and the rate of expansion of keratinocyte outgrowths from eccrine sweat glands parallels the rate of reepithelialization. This novel appreciation of the unique importance of eccrine sweat glands for epidermal repair may be exploited to improve our approaches to understanding and treating human wounds. (15)

Improved understanding of cutaneous healing has guided more sophisticated and targeted approaches to enhancing injury repair. As a foundation to treating all wounds, optimization of controllable healing factors remains a central principle. This can include nutritional support, smoking cessation, blood perfusion and fluid drainage, infection clearance, and mechanical protection. Simple techniques such as maintaining a clean but moist wound environment with occlusive dressings (122) help to accelerate re-epithelialization and alter the inflammatory milieu to favor better healing. Mechanical support at sites of high skin tension reduces the development of hypertrophic scars and keloids.(121,123)

A wide variety of experimental approaches have been developed to incorporate stem cell-based therapies in cutaneous wound healing. Stem cells can be delivered in conjunction with skin composites or by various other methods, including direct application. For skin wounds, major efforts have focused on the use of epidermal progenitor cells, mesenchymal stroma/stem cells, adipose tissue-derived stem cells, and induced pluripotent stem cells.(121)

A goal of regenerative medicine is to replace or 


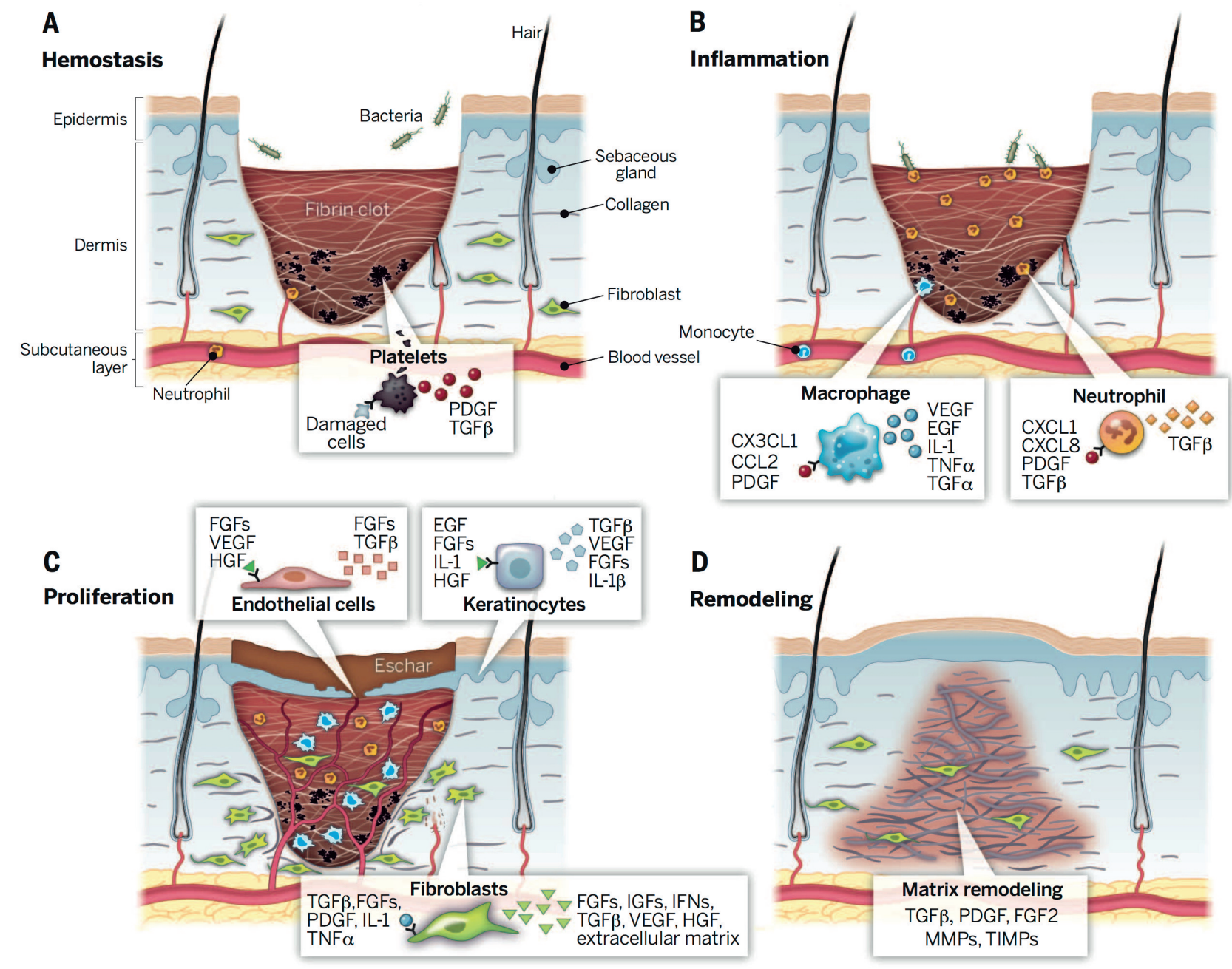

Figure 5. Stages of wound healing. Wound healing is classically divided into four stages: (A) hemostasis, (B) inflammation, (C) proliferation, and (D) remodeling. Each stage is characterized by key molecular and cellular events and is coordinated by a host of secreted factors that are recognized and released by the cells of the wounding response.(121) (Adapted with permission from American Association for the Advancement of Science).

regenerate whole body organs. For skin grafting, this would mean the restoration of all functional components, including hair follicles, sweat glands, and nerves. Although there is no perfect skin substitute currently available, rapid developments in understanding skin development and wound repair, together with advances in stem cell and tissue bioengineering, provide hope that such a product represents a tractable goal in the future.

\section{Skin Stem Cells Exhaustion and Aging}

The skin shows profound structural and functional changes with age, including dermal and epidermal thinning, reduction in epidermal proliferation and injury repair, loss of dermal elasticity and wrinkling, and graying, thinning and loss of hair. Aged hair follicle stem cells maintain their numbers and gene signatures. However, telogen lengthens with age, suggesting that quiescent hair follicle stem cells become increasingly resistant to activation. $(124,125)$

Skin ageing is likely to be a combination of the natural process of cellular decay and the result of the exposure to continuous external aggressions such as ultraviolet light. In aged human skin, the undulating pattern that forms the rete ridges of the basal layer is flattened, and the expression of stem cell markers is lower $(35,39,126)$, which results in a reduced potential to self-renew in vitro (127). In aged mouse epidermis, although the morphology of the hair follicles and sebaceous glands is altered (122), the total number of bulge stem cells remains constant $(17,128,129)$. Although some studies in mice suggest that epidermal stem cells are retained during aging $(17,128)$, aged human keratinocyte stem cells exhibit decreased colony-forming ability (127), suggesting that undiscovered stem cell changes may be involved in epidermal aging. Indeed, the skin contains many 
individual, well-characterized stem cell populations, which not only highlights the complexity of the skin hierarchy, but also suggests that discrete populations may undergo age-associated changes that might ultimately impact tissue function.(129)

The reasons underlying skin stem cell ageing are not entirely clear. Bulge stem cells do not prevent their DNA from accumulating mutations through asymmetrical chromosome segregation during mitosis $(130,131)$, but they inherently repair DNA damage faster than other hair follicle cells by expressing more B cell lymphoma 2 (BCL-2) and transiently stabilizing $\mathrm{p} 53$, as well as through breast cancer 1 (BRCA1)-dependent survival mechanisms $(132,133)$. They also have the longer telomeres and lower rates of telomere shortening upon division, which might prevent replicationinduced genomic instability.(128,134) Nevertheless, aged bulge stem cells show reduced clonogenic potential. $(10,129)$ One possible cause might rely on the progressive alteration of the pathways that control their self-renewal or the transition from quiescence to activation, both resulting in bulge stem cell ageing. $(60,135)$

Epidermal integrity is a complex process established during embryogenesis and maintained throughout the organism lifespan by epithelial stem cells. Although Wnt regulates normal epithelial stem cell renewal, aberrant Wnt signaling can contribute to cancerous growth.(135) Wnt caused the rapid growth of the hair follicles, but this was followed by epithelial cell senescence, disappearance of the epidermal stem cell compartment, and progressive hair loss. Although Wnt1 induced the activation of $\beta$-catenin and the mammalian target of rapamycin (mTOR) pathway, both hair follicle hyperproliferation and stem cell exhaustion were strictly dependent on mTOR function. These findings suggest that whereas activation of $\beta$-catenin contributes to tumor growth, epithelial stem cells may be endowed with a protective mechanism that results in cell senescence upon the persistent stimulation of proliferative pathways that activate mTOR, ultimately suppressing tumor formation. (135)

Two markers of human IFE stem cells are MCSP and neuron-glial antigen 2 (NG2) (39) and high levels of $\beta 1$ integrins $(35,36,136)$. The reduction in $\beta 1$ integrin levels and MCSP expression with advancing age may also contribute to age-associated changes in dermal thickness and skin vascularization. Integrins collaborate with growth factor receptors to influence growth factor production and responsiveness $(137,138)$, and MCSP can enhance integrindependent signaling $(126,139)$.

Microenvironmental and systemic changes might also affect bulge and interfollicular stem cell ageing. In aged skin, dermal cellularity and thickness decrease, the subcutaneous fat layer thickens and the presence of immune cells is reduced.(17) Changes in the expression of ECM proteins and collagen deposition also correlate with ageing. (62)

\section{Conclusion}

In the past years, our view of the mechanisms that govern skin homeostasis and regeneration have markedly changed. New populations of stem cells have been identified that behave spatio-temporally differently in healthy tissues and in situations of damage, indicating that a great level of stem cell heterogeneity is present in the skin. A key process in organ homeostasis is the mobilization of stem cells out of their niches.

Recent findings have brought the complexity of cellular and molecular regulators within the skin stem cell niche during development, homeostasis, injury, aging and cancer. With its rich cellular composition, the skin will continue to serve as an important paradigm in the quest to understand stem cell niches. In the era of tissue engineering, driven by the hope that in the future we will be able to manipulate stem cell behavior in situ, suppress tumor formation and progression and grow functional tissues for regenerative medicine.

\section{References}

1. Solanas G, Benitah SA. Regenerating the skin: a task for the heterogeneous stem cell pool and surrounding niche. Nat Rev Mol Cell Biol. 2013; 14: 737-48.

2. Fuchs E. The tortoise and the hair: slow-cycling cells in the stem cell race. Cell. 2009; 137: 811-9.

3. Morris RJ, Liu Y, Marles L, Yang Z, Trempus C, Li S, et al. Capturing and profiling adult hair follicle stem cells. Nat Biotechnol. 2004; 22 : 411-7.

4. Tumbar T, Guasch G, Greco V, Blanpain C, Lowry WE, Rendl M, et al. Defining the epithelial stem cell niche in skin. Science. 2004; 303: 359-63.

5. Jaks V, Barker N, Kasper M, van Es JH, Snippert HJ, Clevers H, et al. Lgr5 marks cycling, yet long-lived, hair follicle stem cells. Nat Genet. 2008; 40: 1291-9.

6. Snippert HJ, Haegebarth A, Kasper M, Jaks V, van Es JH, Barker N, et al. Lgr6 marks stem cells in the hair follicle that generate all cell lineages of the skin. Science. 2010; 327: 1385-9.

7. Jensen KB, Collins CA, Nascimento E, Tan DW, Frye M, Itami $\mathrm{S}$, et al. Lrig1 expression defines a distinct multipotent stem cell population in mammalian epidermis. Cell Stem Cell. 2009; 4: 427 39.

8. Jensen UB, Yan X, Triel C, Woo SH, Christensen R, Owens DM. A distinct population of clonogenic and multipotent murine follicular 
keratinocytes residing in the upper isthmus. J Cell Sci. 2008; 121: 609-17.

9. Clayton E, Doupé DP, Klein AM, Winton DJ, Simons BD, Jones PH. A single type of progenitor cellmaintains normal epidermis. Nature. 2007; 446: 185-9.

10. Janich P, Pascual G, Merlos-Suarez A, Batlle E, Ripperger J, Albrecht $\mathrm{U}$, et al. The circadian molecular clock creates epidermal stem cell heterogeneity. Nature. 2011; 480: 209-14.

11. Blanpain C, Fuchs E. Epidermal homeostasis: a balancing act of stem cells in the skin. Nat Rev Mol Cell Biol. 2009; 10: 207-17.

12. Alonso L, Fuchs E. The hair cycle. J Cell Sci. 2006; 119: 391-3.

13. Fuchs E, Horsley V. More than one way to skin. Genes Dev. 2008; 22: 976-85.

14. Levy V, Lindon C, Zheng Y, Harfe BD, Morgan BA. Epidermal stem cells arise from the hair follicle after wounding. FASEB J. 2007; 21: 1358-66.

15. Rittie L, Sachs DL, Orringer JS, Voorhees JJ, Fisher GJ. Eccrine sweat glands are major contributors to reepithelialization of human wounds. Am J Pathol 2013; 182: 163-71.

16. McCullough JL, Kelly KM. Prevention and treatment of skin aging. Ann NY Acad Sci. 2006; 1067: 323-31.

17. Giangreco A, Qin M, Pintar JE, Watt FM. Epidermal stem cells are retained in vivo throughout skin aging. Aging Cell. 2008; 7: 250-9.

18. Schepeler T, Page ME, Jensen KB. Heterogeneity and plasticity of epidermal stem cells. Development. 2014; 141: 2559-67.

19. Watt FM. Mammalian skin cell biology: at the interface between laboratory and clinic. Science. 2014; 346: 937-40.

20. Zimmerman A, Bai L, Ginty DD. The gentle touch receptors of mammalian skin. Science. 2014; 346: 950-4.

21. Lo JA, Fisher DE. The melanoma revolution: from UV carcinogenesis to a new era in therapeutics. Science. 2014 ; 346: 945-9.

22. Belkaid Y, Segre JA. Dialogue between skin microbiota and immunity. Science. 2014; 346: 954-9.

23. Hsu YC, Li L, Fuchs E. Emerging interactions between skin stem cells and their niches. Nat Med. 2014; 20: 847-56.

24. Lin JY, Fisher DE. Melanocyte biology and skin pigmentation. Nature. 2007; 445: 843-50.

25. Cui R, Widlund HR, Feige E, Lin JY, Wilensky DL, Igras VE, et al. Central role of p53 in the suntan response and pathologic hyperpigmentation. Cell. 2007; 128: 853-64.

26. Paus R, Theoharides TC, Arck PC. Neuroimmunoendocrine circuitry of the 'brain-skin connection'. Trends Immunol. 2006; 27: 32-9.

27. Arck PC, Slominski A, Theoharides TC, Peters EM, Paus R. Neuroimmunology of stress: skin takes center stage. J Invest Dermatol. 2006; 126: 1697-704.

28. Aberg KM, Radek KA, Choi EH, Kim DK, Demerjian M, Hupe M, et al. Psychological stress downregulates epidermal antimicrobial peptide expression and increases severity of cutaneous infections in mice. J Clin Invest. 2007; 117: 3339-49.

29. Slominski A. A nervous breakdown in the skin: stress and the epidermal barrier. J Clin Invest. 2007; 117: 3166-9.

30. Arck P, Paul R. From the brain-skin connection: the neuroendocrineimmune misalliance of stress and itch. Neuroimmunomodulation. 2006; 13: 347-56.

31. Arck P, Handjiski B, Hagen E, Pincus M, Bruenahi C, Bienenstock J, et al. Is there a 'gut-brain-skin axis'? Exp Dermatol. 2010; 19: 4015 .

32. Potten CS, Morris RJ. Epithelial stem cells in vivo. J Cell Sci Suppl. 1988; 10: 45-62.

33. Potten CS. The epidermal proliferative unit: the possible role of the central basal cell. Cell Tissue Kinet. 1974; 7: 77-88.

34. Mascre G, Dekoninck S, Drogat B, Youssef KK, Broheé S,
Sotiropoulou PA, et al. Distinct contribution of stem and progenitor cells to epidermal maintenance. Nature. 2012; 489: 257-62.

35. Jones PH, Watt FM. Separation of human epidermal stem cells from transit amplifying cells on the basis of differences in integrin function and expression. Cell. 1993; 73: 713-24.

36. Jones PH, Harper S, Watt FM. Stem cell patterning and fate in human epidermis. Cell. 1995; 80: 83-93.

37. Li A, Simmons PJ, Kaur P. Identification and isolation of candidate human keratinocyte stem cells based on cell surface phenotype. Proc Natl Acad Sci USA. 1998; 95: 3902-7.

38. Lowell S, Jones P, Le Roux I, Dunne J, Watt FM. Stimulation of human epidermal differentiation by delta-notch signalling at the boundaries of stem-cell clusters. Curr Biol. 2000; 10: 491-500.

39. Legg J, Jensen UB, Broad S, Leigh I, Watt FM. Role of melanoma chondroitin sulphate proteoglycan in patterning stem cells in human interfollicular epidermis. Development. 2003; 130: 6049-63.

40. Jensen KB, Watt FM. Single-cell expression profiling of human epidermal stem and transit-amplifying cells: Lrig1 is a regulator of stem cell quiescence. Proc Natl Acad Sci USA. 2006; 103: 1195863.

41. Luis NM, Morey L, Mejetta S, Pascual G, Janich P, Kuebler B, et al. Regulation of human epidermal stem cell proliferation and senescence requires polycomb-dependent and -independent functions of Cbx4. Cell Stem Cell. 2011; 9: 233-46.

42. Fortunel NO, Hatzfeld JA, Rosemary PA, Ferraris C, Monier MN, Haydont V, et al. Long-term expansion of human functional epidermal precursor cells: promotion of extensive amplification by low TGF-beta1 concentrations. J Cell Sci. 2003; 116: 4043-52.

43. Greco V, Chen T, Rendl M, Schober M, Pasolli HA, Stokes N, et al. A two-step mechanism for stem cell activation during hair regeneration. Cell Stem Cell. 2009; 4: 155-69.

44. Hsu YC, Pasolli HA, Fuchs E. Dynamics between stem cells, niche, and progeny in the hair follicle. Cell. 2011; 144: 92-105.

45. Tumbar T, Guasch G, Greco V, Blanpain C, Lowry WE, Rendl M, et al. Defining the epithelial stem cell niche in skin. Science. 2004; 303: 359-63.

46. Rompolas P, Mesa KR, Greco V. Spatial organization within a niche as a determinant of stem-cell fate. Nature. 2013; 502: 5138.

47. Braun KM, Niemann C, Jensen UB, Sundberg JP, Silva-Vargas V, Watt FM. Manipulation of stem cell proliferation and lineage commitment: visualisation of label-retaining cells in wholemounts of mouse epidermis. Development. 2003; 130: 5241-55.

48. Taylor G, Lehrer MS, Jensen PJ, Sun TT, Lavker RM. Involvement of follicular stem cells in forming not only the follicle but also the epidermis. Cell. 2000; 102: 451-61.

49. Ghazizadeh S, Taichman LB. Multiple classes of stem cells in cutaneous epithelium: a lineage analysis of adult mouse skin. EMBO J. 2001; 20: 1215-22.

50. Ito M, Liu Y, Yang Z, Nguyen J, Liang F, Morris RJ, et al. Stem cells in the hair follicle bulge contribute to wound repair but not to homeostasis of the epidermis. Nat Med. 2005; 11: 1351-4.

51. Oshima H, Rochat A, Kedzia C, Kobayashi K, Barrandon Y. Morphogenesis and renewal of hair follicles from adult multipotent stem cells. Cell. 2001; 104: 233-45.

52. Blanpain C, Lowry WE, Geoghegan A, Polak L, Fuchs E. Selfrenewal, multipotency, and the existence of two cell populations within an epithelial stem cell niche. Cell. 2004; 118: 635-48.

53. Trempus CS, Morris RJ, Bortner CD, Cotsarelis G, Faircloth RS, Reece JM, et al. Enrichment for living murine keratinocytes from the hair follicle bulge with the cell surface marker CD34. J Invest Dermatol. 2003; 120: 501-11. 
54. Claudinot S, Nicolas M, Oshima H, Rochat A, Barrandon Y. Longterm renewal of hair follicles from clonogenic multipotent stem cells. Proc Natl Acad Sci USA. 2005; 102: 14677-82.

55. Xie T, Spradling AC. A niche maintaining germ line stem cells in the Drosophila ovary. Science. 2000; 290: 328-30.

56. Sato T, van Es JH, Snippert HJ, Stange DE, Vries RG, van den Born $\mathrm{M}$, et al. Paneth cells constitute the niche for Lgr5 stem cells in intestinal crypts. Nature. 2011; 469: 415-8.

57. Hsu YC, Fuchs E. A family business: stem cell progeny join the niche to regulate homeostasis. Nat Rev Mol Cell Biol. 2012; 13: 103-14.

58. Hsu YC, Li L, Fuchs E. Transit-amplifying cells orchestrate stem cell activity and tissue regeneration. Cell. 2014; 157: 935-49.

59. Fujiwara H, Ferreira M, Donati G, Marciano DK, Linton JM, Sato Y, et al. The basement membrane of hair follicle stem cells is a muscle cell niche. Cell. 2011; 144: 577-89.

60. Chen T, Heller E, Beronja S, Oshimori N, Stokes N, Fuchs E. An RNA interference screen uncovers a new molecule in stem cell selfrenewal and long-term regeneration. Nature. 2012; 485: 104-8.

61. Toyoshima KE, Asakawa K, Ishibashi N, Toki H, Ogawa M, Hasegawa $\mathrm{T}$, et al. Fully functional hair follicle regeneration through the rearrangement of stem cells and their niches. Nat Commun. 2012; 3: 784. doi: $10.1038 /$ ncomms 1784 .

62. Watt FM, Fujiwara H. Cell-extracellular matrix interactions in normal and diseased skin. Cold Spring Harb Perspect Biol. 2011; 3: a005124. doi: 10.1101/cshperspect.a005124.

63. Blanpain C, Fuchs E. Stem cell Plasicity. Plasticity of epithelial stem cells in tissue regeneration. Science. 2014; 344: 1242281. doi: 10.1126/science. 1242281 .

64. Potten CS, Saffhill R, Maibach HI. Measurement of the transit time for cells through the epidermis and stratum corneum of the mouse and guinea-pig. Cell Tissue Kinet. 1987; 20: 461-72.

65. Potten CS. Cell replacement in epidermis (keratopoiesis) via discrete units of proliferation. Int Rev Cytol. 1981; 69: 271-318.

66. Potten CS, Wichmann HE, Loeffler M, Dobek K, Major D. Evidence for discrete cell kinetic subpopulations in mouse epidermis based on mathematical analysis. Cell Tissue Kinet. 1982; 15: 305-29.

67. Potten CS, Loeffler M. Epidermal cell proliferation. I. Changes with time in the proportion of isolated, paired and clustered labelled cells in sheets of murine epidermis. Virchows Arch B Cell Pathol Incl Mol Pathol. 1987; 53: 279-85.

68. Mackenzie IC. Retroviral transduction of murine epidermal stem cells demonstrates clonal units of epidermal structure. J Invest Dermatol. 1997; 109: 377-83.

69. Kolodka TM, Garlick JA, Taichman LB. Evidence for keratinocyte stem cells in vitro: long term engraftment and persistence of transgene expression from retrovirus-transduced keratinocytes. Proc Natl Acad Sci USA. 1998; 95: 4356-61.

70. Ghazizadeh S, Taichman LB. Organization of stem cells and their progeny in human epidermis. J Invest Dermatol. 2005; 124: 367-72.

71. Ro S, Rannala B. A stop-EGFP transgenic mouse to detect clonal cell lineages generated by mutation. EMBO Rep. 2004; 5: 914-20.

72. Ro S, Rannala B. Evidence from the stop-EGFP mouse supports a niche-sharing model of epidermal proliferative units. Exp Dermatol. 2005; 14: 838-43.

73. Doupé DP, Klein AM, Simons BD, Jones PH. The ordered architecture of murine ear epidermis ismaintained by progenitor cells with random fate. Dev Cell. 2010; 18: 317-23.

74. Potten CS, Booth C. Keratinocyte stem cells: a commentary. J Invest Dermatol. 2002; 119: 888-99.

75. Blanpain C, Horsley V, Fuchs E. Epithelial stem cells: turning over new leaves. Cell. 2007; 128: 445-58.
76. Li A, Pouliot N, Redvers R, Kaur P. Extensive tissue-regenerative capacity of neonatal human keratinocyte stem cells and their progeny. J Clin Invest. 2004; 113: 390-400.

77. Mannick J, Alzayady K, Ghazizadeh S. Regeneration of multilineage skin epithelia by differentiated keratinocytes. J Invest Dermatol. 2010; 130: 388-97.

78. Sharpe PT, Young CS. Test-tube teeth. Sci Am. 2005; 293: 34-41.

79. González F, Boué S, Izpisúa Belmonte JC. Methods for making induced pluripotent stem cells: reprogramming à la carte. Nat Rev Genet. 2011; 12: 231-42.

80. Priya SG, Jungvid H, Kumar A. Skin tissue engineering for tissue repair and regeneration. Tissue Eng Part B Rev. 2008; 14: 105-18.

81. Nishida K, Yamato M, Hayashida Y, Watanabe K, Maeda N, Watanabe $\mathrm{H}$, et al. Functional bioengineered corneal epithelial sheet grafts from corneal stem cells expanded ex vivo on a temperatureresponsive cell culture surface. Transplantation. 2004; 77: 379-85.

82. Pispa J, Thesleff I. Mechanisms of ectodermal organogenesis. Dev Biol. 2003; 262: 195-205.

83. Bianchini C, Pelucchi S, Galassi G, Mandrioli G, Ciorba A, Pastore A. Use of autologous dermal graft in the treatment of parotid surgery wounds for prevention of neck scars: preliminary results. $\mathrm{J}$ Otolaryngol Head Neck Surg. 2008; 37: 174-8.

84. Nakao K, Morita R, Saji Y, Ishida K, Tomita Y, Ogawa M, et al. The development of a bioengineered organ germ method. Nat Methods. 2007; 4: 227-30.

85. Hoffman RM. The pluripotency of hair follicle stem cells. Cell Cycle. 2006; 5, 232-3.

86. Chuong CM, Wu P, Plikus M, Jiang TX, Bruce Widelitz R. Engineering stem cells into organs: topobiological transformations demonstrated by beak, feather, and other ectodermal organ morphogenesis. Curr Top Dev Biol. 2006; 72: 237-74.

87. Stenn KS, Paus R. Controls of hair follicle cycling. Physiol Rev. 2001; 81: 449-94.

88. Morris RJ, Liu Y, Marles L, Yang Z, Trempus C, Li S, et al. Capturing and profiling adult hair follicle stem cells. Nat Biotechnol. 2004; 22: 411-7.

89. Fuchs E, Tumbar T, Guasch G. Socializing with the neighbors: stem cells and their niche. Cell. 2004; 116: 769-78.

90. Huelsken J, Vogel R, Erdmann B, Cotsarelis G, Birchmeier W. beta-Catenin controls hair follicle morphogenesis and stem cell differentiation in the skin. Cell. 2001; 105: 533-45.

91. Reddy S, Andl T, Bagasra A, Lu MM, Epstein DJ, Morrisey EE, et al. Characterization of Wnt gene expression in developing and postnatal hair follicles and identification of Wnt5a as a target of Sonic hedgehog in hair follicle morphogenesis. Mech Dev. 2001; 107: 69-82.

92. Lo Celso C, Prowse DM, Watt FM. Transient activation of betacatenin signalling in adult mouse epidermis is sufficient to induce new hair follicles but continuous activation is required to maintain hair follicle tumours. Development. 2004; 131: 1787-99.

93. Lowry WE, Blanpain C, Nowak JA, Guasch G, Lewis L, Fuchs E. Defining the impact of beta-catenin/Tcf transactivation on epithelial stem cells. Genes Dev. 2005; 19: 1596-611.

94. Plikus MV, Mayer JA, de la Cruz D, Baker RE, Maini PK, Maxson R, et al. Cyclic dermal BMP signalling regulates stem cell activation during hair regeneration. Nature. 2008; 451: 340-4.

95. Yamao M, Inamatsu M, Ogawa Y, Toki H, Okada T, Toyoshima $\mathrm{KE}$, et al. Contact between dermal papilla cells and dermal sheath cells enhances theability of DPCs to induce hair growth. J Invest Dermatol. 2010; 130: 2707-18.

96. Jahoda CA, Whitehouse J, Reynolds AJ, Hole N. Hair follicle dermal cells differentiate into adipogenic and osteogenic lineages. Exp 
Dermatol. 2003; 12: 849-59.

97. Nishimura EK, Jordan SA, Oshima H, Yoshida H, Osawa M, Moriyama M, et al. Dominant role of the niche in melanocyte stemcell fate determination. Nature. 2002; 416: 854-60.

98. Nishimura EK, Granter SR, Fisher DE. Mechanisms of hair graying: incomplete melanocyte stem cell maintenance in the niche. Science. 2005; 307: 720-4.

99. Kunisada T, Yoshida H, Yamazaki H, Miyamoto A, Hemmi H, Nishimura E, et al. Transgene expression of steel factor in the basal layer of epidermis promotes survival proliferation differentiation and migration of melanocyte precursors. Development. 1998; 125: 2915-23.

100. Fuchs E. Scratching the surface of skin development. Nature. 2007; 445: 834-42.

101. Rendl M, Polak L, Fuchs E. BMP signaling in dermal papilla cells is required for their hair follicle-inductive properties. Genes Dev. 2008; 22: 543-57.

102. Lindner G, Botchkarev VA, Botchkareva NV, Ling G, van der Veen C, Paus R. Analysis of apoptosis during hair follicle regression (catagen). Am J Pathol. 1997; 151: 1601-17.

103. Hardy MH. The secret life of the hair follicle. Trends Genet. 1992; 8: 55-61.

104. Chuong CM, Cotsarelis G, Stenn K. Defining hair follicles in the age of stem cell bioengineering. J Invest Dermatol. 2007; 127: 2098100

105. Jahoda CA, Horne KA, Oliver RF. Induction of hair growth by implantation of cultured dermal papilla cells. Nature. 1984; 311: 560-2.

106. Jahoda CA, Oliver RF, Reynolds AJ, Forrester JC, Horne KA. Human hair follicle regeneration following amputation and grafting into the nude mouse. J Invest Dermatol. 1996; 107: 804-7.

107. Stenn K, Parimoo S, Zheng Y, Barrows T, Boucher M, Washenik K. Bioengineering the hair follicle. Organogenesis. 2007; 3: 6-13.

108. Weinberg WC, Goodman LV, George C, Morgan DL, Ledbetter S, Yuspa SH, et al. Reconstitution of hair follicle development in vivo: determination of follicle formation, hair growth, and hair quality by dermal cells. J Invest Dermatol. 1993; 100: 229-36.

109. Kishimoto J, Ehama R, Wu L, Jiang S, Jiang N, Burgeson RE. Selective activation of the versican promoter by epithelialmesenchymal interactions during hair follicle development. Proc Natl Acad Sci USA. 1999; 96: 7336-41.

110. Lichti U, Anders J, Yuspa SH. Isolation and short-term culture of primary keratinocytes, hair follicle populations and dermal cells from newborn mice and keratinocytes from adult mice for in vitro analysis and for grafting to immunodeficient mice. Nat Protoc. 2008; 3: 799-810

111. Zheng Y, Du X, Wang W, Boucher M, Parimoo S, Stenn K. Organogenesis from dissociated cells: generation of mature cycling hair follicles from skin-derived cells. J Invest Dermatol. 2005; 124: $867-76$.

112. Gilmour SK, Teti KA, Wu KQ, Morris RJ. A simple in vivo system for studying epithelialization, hair follicle formation, and invasion using primary epidermal cells from wild-type and transgenic ornithine decarboxylase- overexpressing mouse skin. J Invest Dermatol. 2001; 117: 1674-6.

113. Rabbani P, Takeo M, Chou W, Myung P, Bosenberg M, Chin L, et al. Coordinated activation of Wnt in epithelial and melanocyte stem cells initiates pigmented hair regeneration. Cell. 2011; 145: 941-55.

114. MacNeil S. Progress and opportunities for tissue-engineered skin. Nature. 2007; 445: 874-80.

115. Cerqueira MT, Marques AP, Reis RL. Using stem cells in skin regeneration: possibilities ad reality. Stem Cell Dev. 2012; 21:
1201-14.

116. Sen CK, Gordillo GM, Roy S, Kirsner R, Lambert L, Hunt TK, et al. Human skin wounds: a major and snowballing threat to public health and the economy. Wound Repair Regen. 2009; 17: 763-71.

117. Peck MD. Epidemiology of burns throughout the world. Part I: Distribution and risk factors. Burns. 2011; 37: 1087-100.

118. Butler KL, Goverman J, Ma H, Fischman A, Yu YM, Bilodeau M, et al. Stem cells and burns: review and therapeutic implications. J Burn Care Res. 2010; 31: 874-81.

119. Jones JE, Nelson EA, Al-Hity A. Skin grafting for venous leg ulcers. Cochrane Database Syst Rev. 2013; 1: CD001737. doi: 10.1002/14651858.CD001737.pub4.

120. Gurtner GC, Werner S, Barrandon Y, Longaker MT. Wound repair and regeneration. Nature. 2008; 453: 314-21.

121. Sun BK, Siprashvili Z, Khavari PA. Advances in skin grafting and treatment of cutaneous wounds. Science. 2014; 346: 941-5.

122. Eaglstein WH. Moist wound healing with occlusive dressings: a clinical focus. Dermatol Surg. 2001; 27: 175-81.

123. Ogawa R. The most current algorithms for the treatment and prevention of hypertrophic scars and keloids. Plast Reconstr Surg. 2010; 125: 557-68.

124. Keyes BE, Segal JP, Heller E, Lien WH, Chang CY, Guo X, et al Nfatc1 orchestrates aging in hair follicle stem cells. Proc Natl Acad Sci USA. 2013; 110: E4950-9.

125. Chen CC, Murray PJ, Jiang TX, Plikus MV, Chang YT, Lee OK, et al. Regenerative hair waves in aging mice and extra-follicular modulators follistatin, dkk1, and sfrp4. J Invest Dermatol. 2014; 134: 2086-96.

126. Giangreco A, Goldie SJ, Failla V, Saintigny G, Watt FM. Human skin aging is associated with reduced expression of the stem cell markers beta1 integrin and MCSP. J Invest Dermatol. 2010; 130: 604-8.

127. Barrandon Y, Green H. Three clonal types of keratinocyte with different capacities for multiplication. Proc Natl Acad Sci USA. 1987; 84: 2302-6.

128. Stern MM, Bickenbach JR. Epidermal stem cell are resistant to cellular aging. Aging Cell. 2007; 6: 439-52.

129. Doles J, Storer M, Cozzuto L, Roma G, Keyes WM. Age-associated inflammation inhibits epidermal stem cell function. Genes Dev. 2012; 26: 2144-53

130. Waghmare SK, Bansal R, Lee J, Zhang YV, McDermitt DJ, Tumbar T. Quantitative proliferation dynamics and random chromosome segregation of hair follicle stem cells. EMBO J. 2008; 27: 1309-20.

131. Sotiropoulou PA, Candi A, Blanpain C. The majority of multipotent epidermal stem cells do not protect their genome by asymmetrical chromosome segregation. Stem Cells. 2008; 26: 2964-73.

132. Sotiropoulou PA, Candi A, Mascré G, De Clercq S, Youssef KK, Lapouge $\mathrm{G}$, et al. $\mathrm{Bcl}-2$ and accelerated DNA repair mediates resistance of hair follicle bulge stem cells to DNA-damage-induced cell death. Nature Cell Biol. 2010; 12: 572-82.

133. Sotiropoulou PA, Karambelas AE, Debaugnies M, Candi A, Bouwman P, Moers V, et al. BRCA1 deficiency in skin epidermis leads to selective loss of hair follicle stem cells and their progeny. Genes Dev. 2013; 27: 39-51.

134. Flores I, Cayuela ML, Blasco MA. Effects of telomerase and telomere length on epidermal stem cell behavior. Science. 2005; 309: 1253-6.

135. Castilho RM, Squarize CH, Chodosh LA, Williams BO, Gutkind JS. mTOR mediates Wnt-induced epidermal stem cell exhaustion and aging. Cell Stem Cell. 2009; 5: 279-89.

136. Jensen UB, Lowell S, Watt FM. The spatial relationship between stem cells and their progeny in the basal layer of human epidermis: a new view based on whole-mount labelling and lineage analysis. Development. 1999; 126: 2409-18. 
137. Legate KR, Wickstrom SA, Fassler R. Genetic and cell biological analysis of integrin outside-in signaling. Genes Dev. 2009; 23: 397 418.

138. Streuli CH, Akhtar N. Signal co-operation between integrins and other receptor systems. Biochem J. 2009; 418: 491-506.
139. Yang J, Price MA, Neudauer CL, Wilson C, Ferrone S, Xia H, et al. Melanoma chondroitin sulfate proteoglycan enhances FAK and ERK activation by distinct mechanisms. J Cell Biol. 2004; 165: 881-91. 